\title{
A sociological analysis of the roots of crime in the family. (Case study in Durres)
}

\author{
Marjeta Milloshi \\ jetamilloshi@yahoo.com
}

\begin{abstract}
In the area of Ex Keneta Durres after 90' was populated by rural residents coming from other provinces. It is a poor area, an informal area in construction and employment of residents. Not all residents are integrated in social life.Analysis of this study aims to study crime and domestic violence by first polidimension all related factors to explain the social roots of crime in families.Domestic crime is one of the social problems in our country. Statistical data for the City of Durres speak for counting crimes increased violence, and also show that the family is getting "dangerous place" of crime. The focus of the study is the overall situation of social, economic, cultural, emotional, psychological, former residents of the swamp. Factors which are sources that generate domestic violence or crimes in the family. In the area of Ex Keneta Durres in july of 2004 with the decision of the Municipal Council of Durres was approved as the new administrative unit, comprising Region No. 6 The area of Ex Keneta is a new residential area, increase the number of arrivals from day to day. in this structure combines elements of various subcultures. The analysis aims at studying the social roots of crime that will be done from the perspective of theoretical paradigms. It also focuses on the role of the state and other agencies to create socialization-economic stability, but also to create conditions for "mental health" of citizens. Social problems of contemporary society have their roots in the past, the consequences in the present and in the future. The importance of the study appear in several elements: -A heterogeneity area residents coming from different provinces have different subcultures. -An area dominated traditional families with a large number of members, with some garland. -Domestic Relations built on customary mentality. -An area where there is fragmentation of families as the result of immigration. "The comunication matrix" is very imported in the socilism of the family mambers. For the realization of this study i have selected qualitative methods, such as:free intervists, structured. The study data are based on some searching methods: Quantitative methods, qualitative; Structured interviews; Official data from the Police Departament of Durres; The review of printed media; Survey 200.
\end{abstract}

Keywords: Aggression,crime,deviance, the comunication matrix, integration, social interaction

\section{Introduction}

Albanian society within the family organization changes have occurred. Albanian families,family nucleus, which consists on the coexistence of parents with children in the family, though it is not completely separate from the ties of kinship.Marriages in our country already constructed on the basis of romantic love, the main impact is made affective individualization.As in other places emphasis on personal pleasure in marriage has brought several requirements that can not be realized, it has contributed in recent years to increase the number of divorces. "Affective individualism, forming the basis of marriage, the change affects the man-woman relationships, family is a realization private world where emotional or sexual intimacy between husband and wife Is given primary importance".(Gidden,A,1997:377).

From a moral and social, family and society are currently in the process of transition from chaotic nature traditionalist toward change, adaptation to time and the imperatives of modern civilization. in correlation between family and society, it is strange that it profoundly affects negatively, breaking the old equilibrium between the individual, the family and family relations with society. Showing balances delicate, fragile. This is evident in phenomena that prove the lack of stability within the family, which is obviously reflected in social life kaotizmi the Albanian society is facing today."Variance misunderstandings, lack of communication, astiff and nervous behavior coupled with offensive words. The parent hits a child, young people suffer, especially girls, from various Forms of depression".(Fuga,A,2007:9).

Sociological studies, domestic violenceis considered as the dark sides of family life. Domestic violence has become more wide spread in traditional societies, with a higher specific gravity of rural populations. Such is the Albanian society now a days. About $55 \%$ of women and $54 \%$ of men Living in rural areas.(ADHS 2008-09:37).

On the out skirts of the city of Durres his social problem continues to be quite disturbing rape of women and children by husbands or their fathers. Interviews conducted in the former swamp area in Durres talk about this aspect.

-Mrs.SK 27 years old has been out of work 10 years and married for 8 years and she lives in the former swamp area. Her family consists of 8persons (spouse and two children, two brothers in law, mother and father in law). House hold in come int his work provided by the husband and brothers in law.Regarding its communication with parents partner she says that this relationship is not good but many tolerate all that I escaped from the family and that there cannot come back.She is 
not independet in making decisions but above all the others who decide to, it also means that no one listen to my decisions. Of course in this family influence patriarchy and forms of violence ranging from psychological. Mother in law helps a little house work and not allow it to go to work. Says there has never thought to continue further education. If no one is addressing the economic needs mother in law and father in law because those people are holding family in come. When asked Which stance when carrying spouse conflict occurs between the bride and mother in law, she says he cried in front of her mother in law and he is on the side of it.

- Mrs.DH 32 years shop keeper has about 14 years of marriage and for 10 years she lived in this area.Her family is composed of eight persons (spouses, 4 children, mother in law and father in law). Revenues in this family provides by the spouse who works in immigration and mother in law and father in law are retired. Communication between the bride and the partner parents are delicate. She says it is not independent in making decisions even she says she has never taken any decision. in this patriarchal family has influence through the interview and understand that there is psychological violence. It also states that it is self that makes all the house chores. Mrs.DH says he has always had the desire to stay in school after married but did not let go. While this phenomenon becomes even more disturbing for the fact that many womens, because of the violence, psychosis and customary codes, not vilify physical and psychological violence exercised against them.

\section{Methodology}

Quantitative methods,qualitative and structured interviews. for the realization of this study are used combined methods. There were completed 200 survey of the citizens of Durres, and some observations on the family environment.The macrosociological and microsociological analysis helped me with the datas to be near the reality. The survey contains open and closed questions that enables the extractions of necessary results and informations.

Analysis of literature is part of this study.

\section{The study hypothesis}

Some of main hypothesis that are going to be treated in this study are:

Is crime a growing tendence in the city of Durres?

Is the family today a "dangerous place" of crime?

Does the educational level crime family?

Does the poverty affect in the growing of crime?

\section{The data analysis}

a.The picture of crime in the family refering statistics for the crime in the city of Durres.

In the following table are given official statistics received from the Police Departamant of Durres(year 2011,2012,2013).

$\begin{array}{llll}\text { The Year } & \text { Year 2011 } & \text { Year 2012 } & \text { Year 2013 } \\ \text { The Number of Crime } & 265 & 342 & \text { 82(January-april) }\end{array}$

The statistc framework presents an alarming situation of crimes.Violence and crime are growing up from year to year.From year 2011 to 2012 we had 72 cases more.

b. The opinions of the citizens of Durres for crime in family.

Demographisis of inquiry

Residents in Durres Number

The background of residence
$60 \%$

$26 \%$ 


$\begin{array}{lll}\text { ISSN 2411-9563 (Print) } & \text { Maropean Journal of Social Sciences } & \text { Vougust 2014 } \\ \text { IISSN 2312-8429 (Online) } & 29 & 14 \% \\ \text { Coming from another city } & 200 & 100 \% \\ \text { Total } & 22 & 11 \% \\ \text { Age } 14-20 & 66 & 33 \% \\ 21-30 & 50 & 25 \% \\ 31-40 & 30 & 15 \% \\ 41-50 & 22 & 11 \% \\ 51-60 & 10 & 0.5 \% \\ 61-70 & 200 & 100 \\ \text { Total } & 122 & 61 \% \\ \text { Females } & 78 & 39 \% \\ \text { Males } & 200 & 100 \% \\ \text { Total } & 18 & 0.9 \% \\ \text { Lower Secondary Education } & 122 & 61 \% \\ \text { Gymnazium } & 60 & 30 \% \\ \text { High School } & 200 & 100 \% \\ \text { Total } & & \end{array}$

The surveyed were asked for the forms of violence in the family. The survey data give this order:

Physical Violence 42\%,Psychological Violence 32\%,Verbal Violence 6\%,Sexual Violence 7\%

Economic Violence 13\%.

It is seen with importance the analysis of this question interlacing with the knowledge that have

\section{The residents about the violence in the family.}

The highter percentage possesses the physical violence maybe because for the fact that this is the most frequent form that is spoken in the media,followed from the psychological violence. Domestic violence is observed for those families who see the power of the family that belongs to man and he can do what he pleases.

Evolution of the Albanian family, change of classical functions, the relations between family members, is essentially a progress as contradictory and paradoxical. On the one hand facilitate the classical functions of the traditional family is provided for creating more space for freedom and social progress of individuals. These positive changes are essentially chaotic and conflicting. "The public perception of these conceptual changes, structural and spiritual place in Albanian families, by many regarded as" signals "of family disintegration and destruktimit" (Tushi, G, 2009: 319).

If we refer to reality, especially the suburbs of our cities, we note that the transformation is not over yet modern Albanian family typology, because it is still in "transition waves". The purpose of this paper is to sudioj their relationship within the family, between the bride and mother in law, son and wife known as "classic conflict" but also as one of the most difficult interpersonal relations and complicated the family in Albania. To study the dynamics of relationships between mother, son, daughter decided to select the former swamp area, the outskirts of the city of Durres.

The former swamp area is a new neighborhood of the city of Durres, which is populated by migrants recently coming from different areas of the country. Former swamp area in July of 2004 with the decision of the Municipal Council of Durres was approved as the new administrative unit, comprising Region No. 6. Swamp in the former increasing number of newcomers from day to day and has reached 40 thousand inhabitants.

The age structure of the population is young and its residents have come from Mirdita (16.5\%), Puke (11.5\%), Gramsci $(10.25 \%)$, Burrel $(10.25 \%)$ etc.. in this structure combines elements of various subcultures. From the statistical data taken note that municipal units in the area dominated by families with more than one crown inside. These families have brought 
with them not only the style and ways of life of the areas of which come, but the patriarchal authority, traditional building relationships.

Respondents were asked and for aggressive behavior.

What is for you an aggressive behavior?

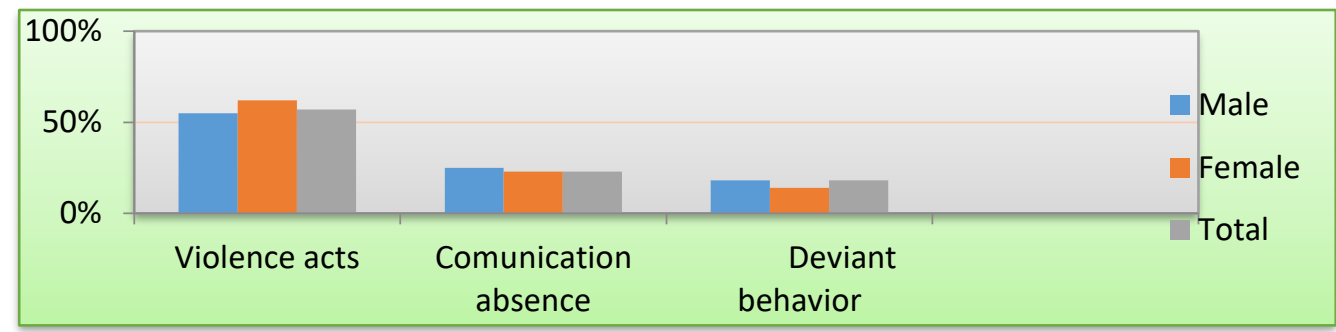

From the data of survey results that the most of the surveyed $62 \%$ females and $55 \%$ males ose $57 \%$ of the surveyed have defined the aggression behavior regarding the concept of violence.Both genres have estimated violence act as e better definition. This is regarding with the fact that every days people are exposed on the danger of aggression as victims,or as wittness of a violence.The aggression behavior is considered as a violent sea with the higher percentage.There are even traditional stereotypes of the society for the males and females that model the behavior of males and females in society.

While a low percentage, $23 \%$, accept that the communication absence produces aggressiveness. $23 \%$ of the females have qualifying the aggressive behavior as a communication absence.From the other side,fast changes in society,the way of living,the facing with norms and new values create a disorentation and suitability absence on the changes that are faced. "The reason is every change,crashing with the inherited institutions of the past,is an difficult inevitable way" (Dyrkheim,E,2004,:46).

It is noted that the tendency to maintain the form of patriarchal marriage within the family noticed mixture of crowns, which in these families is the leading authority in-law. Almost all women are unemployed. Even in these work-family households are seen as two separate areas from each other. Women are responsible for family life, men working life, this picture serves as a contributor to the obstacles facing women's equality, superstitious thoughts and discriminatory behavior. (Basow, Susan; 2003.303). This status is not favorable for women of these families. Almost all accept that being unemployed were obliged to for what they need to seek pre-law, mother in law and husband. They agreed that one of the causes of conflict bride-guy-in law were economic reasons, unemployment, poverty. These causes represent one of the reasons the social conflicts that arise in society. One of the concerns that arise from the interviews was the lack of economic independence is often made that they were passive in decision making, which was expressed from the simple things in family purchase until handling problems and education of their children .

Another cause conflict within the family of former swamp area to report a bride-son-in law, are the relationships that appear pathological jealousy. Most brides to create relationships and conflicts in this report blaming mother in law. I do not know how many are really in this statement. Yes deeply analyzing their responses notices a contradiction. On the one hand almost all know that helps a lot in-law housework, etc. in keeping children and in turn become a cause for jealousy, conflict. Apparently in this conflict-vjehrë bride, a special role because of "double duty" as a boy and as a man needs to play boy. The boy has placed major weight harmonious relations between the bride and mother in law.From interviews admitted that these relationships often finalized with violence: emotional, psychological, physical, and there are cases and death threats. The way a society defines family violence depends on the culture, economic status, religious law a geographical place. (Legal and Social Treatises on the protection from domestic violence Advocacy Center, 2005). There is also a target group of brides, they have men in emigracion.Ato live with the husband. Their economic dependence is evident, for every expense that should be accountable to make laws.

Social disorganization theory, finds the best support in this regard. Having lived in very closed circles social, moral norms or codes fixed in order to freeze, place individual loses the ability to perceive another world, different from what you saw until then. It happens that different individuals have a narrow understanding of these roles, according to their worldview traditionally coded and launched the world understand that there excluding any message, information that comes out of their imaginations (Fuga, A, 2007: 32 ).

The surveyed were asked a question: 
How do you think crime in families in the city of Durres?

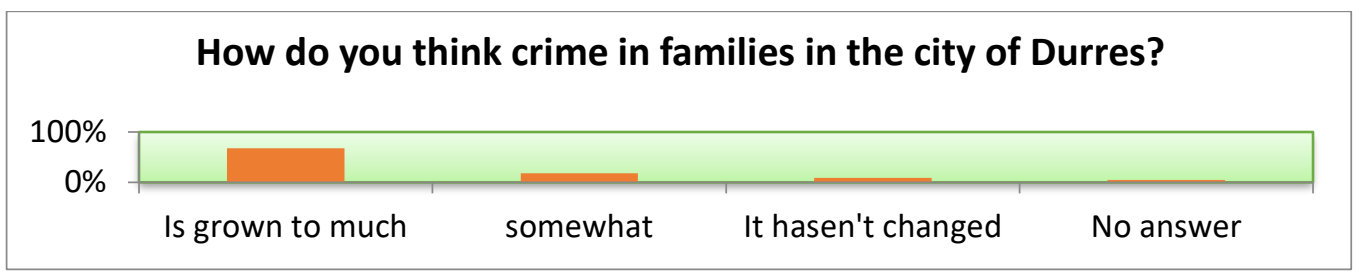

The crime in family is a social problem that has affected our society in last years .From the data of the Police Departament it is noted a tendence that is growing up the crime in the city of Durres.68\% of the surveyed accept that the crime in the family has increased.

$58 \%$ of individs accept that they feel safe in their family.About $10 \%$ of them accept that they don't feel safe in their families. In general the people who are with higher education feel more safe in the family because they are more prepared to afford this situations. Women with higher education have been enacted with the jaqne prepared to encourage communication with their spouses, and are therefore less likely to suffer from domestic violence.

- Mrs. MG 35 years with higher education (Engineer) is 10 years old is married and has 10 years are living in this area. Her family consists of 6 people. Both spouses work and mother in law, father in law take retirement. When asked how is communication with parents partner it says in the beginning were very strained relationship, it stressed every word or gesture while now I try not to be affected adapted at all. in making decisions is independent in most patriarchal rasteve.Influence little while, not violence. Mother in law says it tries to help around the house. If there is no economic need one that has addressed its budget. If there were a conflict between husband and wife vjehrës would not intervene.

To see if the past have been a violence history,the surveyed were asked a question:Have you been violenced in your childhood?

$15.8 \%$ of the surveyed accept the violence in the family.(16.9\% with females and $13.8 \%$ with males).As we see the violence is used at both genres, the higher rates are at females,but they learnd to be obeyed.These individuals learn to be violent in their youth, this behavior was shown as a model to achieve the subjugation of others, obedience. A significant correlation in the study is the analysis of sex offenders and victims of crime in the typical family. "Domestic violence is primarily a male activity"."Family is today the crime dangerous place". It also appears in a study conducted in the city of Durresit.In the family exercise violence:

The husband against his wife, The parents against their children, The sister against her brother,The brother against his siste,

The most endangered groups are:

Females $63.12 \%$,Males 3.20\%,Children $14.43 \%$

A correlation analysis is very important to the roots of violent social variables that lead to the use of violence. The surveyed makes this order:

The economic situation 51\%,Emotional situation 42.2\%,Alkool use 48.3\% Psychological effects of alcohol, which then lead to increase the level of aggression. Alcohol causes a weakening of conceptual skills that lead to misinterpretation of the actions made by other people.

Drug use $20.2 \% .18 \%$ Communication between members.

The analysis of these factors shows that in the first rank by poverty and other patriarchal traditions in the family, which is more sensitive to people coming from rural areas. A significant factor for crimes of violence seen today are alcohol and drugs. Social problems such as unemployment, poverty, lack of confidence in the future, affect the use of alcohol and drugs. Under the effect of these users often create conflicts crimes of violence to violence. Family ties between husband and wife, parent and child, brother and sister, distant cousins can be warm or feeling full, but they can be full and strong tensions that lead people fdrejt despair and a sense of anxiety or guilt. Study the social roots of crime in families constitute a message to all social actors in the life of Durres to undertake urban social policy in the service quality of life of residents and their mental health.

\section{References}


[1] Durkheim,Emile,"Sociological lecture".Publishing House "Plejed", 2004.

[2] Fuga,Artan, "Wheel of Torture" Publishing House"Dudaj", Tirana 2007.

[3] Giddens, Anthony: "Sociology" Cabej, Tirana 2004.

[4] Petijohn "Psychology" Sh, Lila ,Publisher 1996.

[5] Susan A .Basaw, "Stereotypes and gender roles" Publishing House "Dituria" ,Tiranë 2003

[6] Statistics taken from Durres Police Department (2001-2012).

[7] Tushi,Gëzim-“" The Challenge of Civilization" Publishing House "Emal", Tirana 2009

[8] Legal and Social Treatises on the protection from domestic violence. Advocacy Center, 2005.

[9] Demographic and Health Survey 2008-2009 2008-09 ADHS Albania, Tirana, 2010 